\title{
WOULD A STUDENT MIDWIFE RUN POSTNATAL CLINIC MAKE A VALUABLE ADDITION TO MIDWIFERY EDUCATION IN THE UK? - A SYSTEMATIC REVIEW
}

\section{ABSTRACT}

Background - There is growing evidence in the UK that some National Health Service improvements, particularly in the postnatal period, are having an impact on the quality and variety of student midwives' clinical experiences, making it challenging for them to meet the standards set by the regulatory body for midwives and receive a licence to practice. A possible solution to this may be the introduction of a Student Midwife integrated Learning Environment (SMiLE) focusing upon the delivery of postnatal care (PN) through a student run clinic

Objective - To identify the current state of knowledge, regarding the educational outcomes of students who engage with student run clinics (SRC) and the satisfaction of patients who attend them

Search strategy - BNI, CINAHL, EMBASE, MEDLINE were searched for articles published until April 2014.

Selection criteria - Studies nationally and internationally, that were carried out on healthcare students running their own clinics. Outcome measures were the evaluation of educational outcomes of students and client satisfaction were included

Data collection and analysis - Data were extracted, analysed and synthesised to produce a summary of knowledge, regarding the effectiveness of SRC's

Main results - 6 studies were selected for this review

Authors conclusions - The findings that SRC can offer advantages in improving educational outcomes of students and provide an effective service to clients is encouraging. However, given the limited number of high-quality studies included in this review, further research is required to investigate the effectiveness of SRC

Keywords - Student led, student run, midwife, clinic, model of care 


\section{WOULD A STUDENT MIDWIFE RUN POSTNATAL CLINIC MAKE A VALUABLE ADDITION TO MIDWIFERY EDUCATION IN THE UK? - A SYSTEMATIC REVIEW}

\section{Introduction}

Postnatal care is integral to the role of the midwife in many countries and competence in this area is a key activity outlined in the European Union Directives (1). Postnatal care is of global importance however often in the UK it is regarded as the 'Cinderella service' $(2,3,4)$. Postnatal care has been subjected to significant financial cutbacks over the years resulting in new working practices for midwives (5). Midwives are now no longer expected to visit women daily across the hospital and home settings for a minimum of 10 days $(6,7)$ and yet being skilled in the delivery of postnatal care is still a requirement of midwifery training in the UK (6). However, current services redesigned to meet the cost efficiency savings set by the UK government $(8,9,10,5)$ are beginning to have an impact on the clinical learning opportunities for student midwives (11) with the potential of newly qualified midwives lacking competence and confidence in providing high quality safe and effective care to women, their babies and families during this critical time after birth. This potential gap in education offers an opportunity to explore new ways of providing experience in postnatal care. A possible solution to this maybe the introduction of a Student Midwife integrated Learning Environment (SMiLE) focussing upon the delivery of postnatal care through a student led clinic.

\section{Background}

\section{Postnatal care}

Postnatal care focuses upon the provision of a supportive environment in which a woman and her family can adapt to life with their new baby. However, there is limited research on what constitutes best care provision in the postnatal period or the appropriate amount of contact with midwives and other health professionals.

The introduction of selective postnatal visiting in 1986 meant that, midwives were expected to visit postnatal women daily for a minimum of ten days in hospital and home settings (7). Since then this traditional pattern of visits has been replaced by a service that emphasises the importance of "individualised care planning" ensuring the most efficient and effective care for women and babies (5). However, current postnatal care provision in some regions is not meeting the needs of the women who receive it (12) and despite high levels of dissatisfaction reported by women receiving postnatal care it remains the most neglected area of maternity services $(12,18)$.

One way of meeting the financial constraints imposed upon maternity services has been to transfer women into the community within 48 hours of birth (13). Whilst individual studies of the effect of these early discharges on women and babies have been inconclusive, Brown et al's (14) systematic review of early postnatal discharge predicted adverse outcomes for mothers and babies, such as readmissions for medical care and a possible increase in maternal and neonatal morbidity. Despite this, most maternity services have taken an early discharge approach including discharge within 6 hours of an uncomplicated birth. This has not been counterbalanced with increased resources in the community. 
More recently the current services in the UK have seen a change in delivery from traditional home visits, to more women and babies being seen in postnatal clinics. Studies examining home visits compared to postnatal clinics have found no significant difference in overall outcomes $(15,16,17)$. Gagnon et al (16) looked at continuation of breastfeeding and weight gain in infants of women receiving postnatal care in both the home and clinic settings. They found no differences of clinical importance or statistical significance between the groups, but home visits did score higher on maternal satisfaction suggesting that, given a choice, most women would prefer to receive postnatal care at home (16). The issue for many health service providers is that the cost of delivering this service has increased significantly and as a result many National Health Service Trusts no longer consider it to be a cost effective way of providing the service.

Recently the National Federation of Women's Institute (NFWI) (18), warned that current postnatal care services are not meeting the needs of "significant numbers" of women and families across the UK. Based on 5,500 women's experiences of maternity services who gave birth in the last five years, this research highlights significant deficits in postnatal care, with one in five women reporting that they do not see a midwife as often as they would like to in the days and weeks following birth. It further highlights that $25 \%$ of women were unable to make postnatal appointments with midwives at times that were convenient for them and almost $60 \%$ of women surveyed wanted more support with postnatal care. Recommendations from this study encourage maternity services to address staffing levels to drive up standards and improve the quality of postnatal care to women and families as they embark upon parenthood. Similar concerns have been expressed in other countries $(19,2,4)$.

\section{Student Experience of Postnatal Care}

The changes in postnatal care provision are affecting students as well as women. Student midwives are required under Directive 2005/36/EC of the European Parliament (20), to undertake 100 postnatal examinations of women and babies in order to achieve competence and confidence in this area of care. There is growing evidence that some service improvements, particularly in the postnatal period, are having an impact on the quality and variety of student midwives' experiences within their existing clinical placements (11), making it challenging for them to meet the standards set by the regulatory body for midwives and receive a licence to practice (6).

Clinical placements are pivotal in the education of student midwives and have long been viewed as an essential part of undergraduate training (21). These clinical experiences are often viewed as an arena for students to apply their knowledge to practice and to achieve key competencies for professional registration with the $\operatorname{NMC}(6,22)$ and whilst it is acknowledged that the clinical learning environment is an excellent opportunity to acquire experience and to develop competence and confidence amongst students, it does depend on the quality of the learning experience (21). The recent expansion of health professional education has resulted in the requirement for more clinical placements for students and the literature shows that there are inadequacies in quality as a result of these increased numbers of learners $(22,23,24.25)$. These studies conclude that changes in health service provision, high practice hour requirements and increasing numbers of students in practice placements have made it very difficult for universities to meet the regulatory practice requirements of undergraduate nursing and midwifery programmes (23). Pre-registration midwifery has been further challenged by reductions in postnatal visiting by midwives and the expansion of the role of the maternity care support workers, making it difficult for students to achieve sufficient experience to fulfil practice requirements in relation to postnatal care (11). 


\section{Student run clinics}

The challenge of the shortfall in quality and variety of postnatal placement opportunities provides an opportunity to re-evaluate the current model of postnatal education and training, and identify a model that is able to meet the service demands. A student run postnatal clinic overseen by qualified midwives but managed and run by student midwives could be away forward. In an area in the South of England a Student Midwife integrated Learning Environment (SMiLE) will put this concept into practice (26). This innovative model of care is currently being established and is in the process of being formally evaluated. We are not aware of any similar model within the UK or indeed the global midwifery field.

Prior to implementing this model it has been important to look outside of the midwifery field to identify if other professional groups use this approach in healthcare student learning. An international example comes from the medical model of student run clinics (27). Clinics run by medical students have been growing in popularity amongst medical schools mainly in the USA, as a means for enhancing education and integrating the students within community settings (28). They also provide valuable resources to people who are unable to afford medical care by providing their medical services free of charge. This fusion between providing health benefits to disadvantaged people and offering unique educational opportunities to students plays an important role in American society (29). However, despite the growing popularity of student run medical clinics in the USA, the impact they have on educational outcomes of students and client satisfaction is unclear.

This review aims to identify the current state of knowledge, regarding the educational outcomes of students who engage with student run clinics (SRC) and the satisfaction of clients who attend them. A secondary objective was to assess whether a student run clinic could be an effective addition to midwifery education and the postnatal experience of women in the (UK).

\section{Methodology}

The search strategy utilised a PICO template, which was designed to focus and structure clinical questions (29). The population (P) group initially selected was student midwives and the intervention (I) was having engaged in a student run clinic as part of a clinical placement. Following a preliminary review of the literature using the keywords; ("student" AND "midwife" AND "clinic"), that revealed no citations it was clear that the search criteria had to be widened to include studies that had evaluated any healthcare related clinics run by healthcare students or medical students, to ensure a wide a search as possible. The population (P) group was therefore expanded to include any student group in the field of health. Comparison (C) was not specified, but assumed that in most cases it would be standard care. For the purpose of this review we were looking for studies whose outcome (O) measures were educational outcomes of students and satisfaction of clinic users. No geographical limits were imposed in this study as the concept of student run clinics is not prevalent in the UK and are in existence in other countries, in particular the USA. It was noted that midwifery care and education differs in other countries and therefore generalisation will not be possible, however, imposing geographical limits would overlook studies that might provide valuable information.

The following electronic databases were searched from the date when the database commenced up to January 2014; BNI, CINAHL, EMBASE, EBSCO, ERIC, ETHOS, ISI Web of Knowledge and MEDLINE. Varying combinations of keywords; included; "Student led", "student run", "midwife", "postnatal", "clinic", "model of care", "service delivery", "health clinic", "experiential learning", "post*", "healthcare", 
"medical". Boolean operators of AND and OR were also applied in order to combine and focus the search as closely as possible. Spelling of search terms was also of consideration, for example in American databases like CINAHL the keywords used to identify terms may differ from the British spelling or meaning. Examples of these words in relation to this search were postnatal and postpartum. Other databases were also reviewed i.e. NICE, NIHR and Cochrane to identify any existing reviews in this area. Additional supplementations to online databases were from reviewing high quality studies reference lists and reviewing major government policy and documents in the research area and databases of on-going studies such as www.clinicaltrials.gov.

\section{Selection criteria}

Criteria for the search were trials and studies that were carried out with healthcare students running their own clinics as part of their clinical placements. For the purpose of this paper, only studies whose outcome measures were the evaluation of educational outcomes and client satisfaction were included. Studies that looked at students' experiences of attending clinics as part of their clinical placements that were not SRCs, operational aspects or discussions about setting up of SRCs and students' experiences of personal healthcare clinics on campus were all excluded. No restrictions were placed on the ethnicity of participants or geographical location of the study and there was no specific dates set for the inclusion criteria. Language restrictions were imposed to include papers only published in the English language.

\section{Data extraction}

All papers that were potentially eligible for inclusion within this review were initially read and reviewed by two of the researchers using the preview, question, read, summarise (PQRS) system (31) and then if deemed relevant for further assessment were critically appraised using an appraisal tool from the CASP (Critical Skills Appraisal Programme, 2004) (32). The CASP (32) appraisal tools are based on the guides produced by the Evidence Based Medicine Working Group, a group of clinicians at McMaster University, Hamilton, Canada, and colleagues across North America, published in the Journal of the American Medical Association. The tools are designed to address the epidemiological principles behind the study types with particular attention to assessing study validity. The CASP tool assesses both internal and external validity and is therefore appropriate to use in this study and is also the recommended tool for critically appraising healthcare research (33). Once again the critical appraisal of all eligible studies included in this review was undertaken independently by two researchers.

\section{Details of ethical approval}

This systematic review was conducted using data from published manuscripts. Ethical approval was not required. 


\section{Data synthesis}

Simple descriptive summaries were used to tabulate the studies according to key outcomes. This enabled studies to be compared and confirmed that the studies were too heterogeneous to attempt to quantitatively pool study results. Narrative synthesis was used to examine the relationships within and between studies and give an overall assessment of the robustness of the evidence.

\section{Findings}

The search strategy returned 319 citations. One paper was located via a colleague and hand searching methods revealed three further papers that fit the inclusion criteria. Of these, 298 papers were excluded as they related to students' experiences of attending clinics as part of their clinical placements, on campus health promotion clinics, SRCs for training teachers, operational aspects of SRCs or were commentaries. This provided 25 citations for final assessment of eligibility (see fig.1 below). Sixteen were excluded following full text review because they did not report any data on the educational outcomes of students and/or client satisfaction of student run clinics, one was a literature review that contained many of the papers that were already assessed for eligibility or did not meet inclusion criteria and two were discussion papers and not primary sources. This left six papers for final inclusion in the study $(34,35,36.37,38,39)$, see Table 1 for characteristics of the selected studies.

All six studies used student run clinics as an intervention and did not compare the intervention with any alternative, placebo or control group. The majority of the studies were published in peer-reviewed journals, dated between 2001 and 2012 and were undertaken by research teams in the USA $(34,36,37,39)$ and Australia $(35,38)$ (Table 1). Models of service differed between all of these studies (Table 2), with some clinics being based within universities $(35,36,37,38)$ and others in community-based locations $(34,39)$. Single discipline students ran some clinics and others were multidisciplinary, with a combination of medical, health and social care students. In all of the studies, students were overseen in the clinics by practice mentors or university teachers and in some studies a combination of both.

The majority of studies were fairly small in size and none had a control group (Table 1). Three of these studies were undertaken using quantitative methods (37,38,39). Ellet et al (39) used a 5-point, Likert scale, administered through a web-based survey, to measure clients' satisfaction of engaging in the SRC. The anonymous survey consisted of 11 items including, satisfaction in relation to wait times, staff friendliness and hours of operation. Smith et al (37) also used a 5-point, Likert scale web based survey to investigate students perceptions of the value to them of attending a SRC. Warner et al (38) interviewed 20 undergraduate nursing and podiatry students to explore their experiences of running a student run clinic. The effectiveness of this SRC was measured via questionnaires and a post evaluation test of a clinical skill (38). Students were asked to rate their responses to the learning environment, practice discipline specific skills, value of the experience, learning new skills and collaboration with other disciplines. However, whilst the researcher's claim that 20 students were involved in the study, only 12 returned the questionnaire, this results in just a $60 \%$ response rate. They also claim in the abstract that data would be collected by interviews and yet only report the findings from questionnaires and post evaluation tests of a clinical skill.

Three papers reported service evaluation projects $(34,35,36)$. All three used questionnaires to evaluate students' responses to perceived educational value of engaging with SRCs. In the evaluation by Clark et 
al (34), a convenience sample of 49 students across four different groups were surveyed, these included preclinical (foundation programme with no direct client contact) and clinical students, pharmacy and public health students. Using a five-point Likert scale from 0-5 they asked students to rate the SRCs effectiveness in contributing to their personal and professional growth, increasing their understanding of bio psychosocial issues and whether or not they would choose to participate in the programme again. Copley et al (35) evaluated perceived challenges and benefits of engaging in a SRC and whilst the paper states that both students and/or clinical educators views were gathered, it gives no information as to the sample size. Finally, a service evaluation by Gance-Cleveland and Gilbert (36) surveyed 40 paediatric nurse practitioner students who had engaged within a SRC at a local faculty site. The students were asked to complete a questionnaire and a $55 \%$ response rate was achieved. The paper mentions that the responses were collected from three open-ended questions but it fails to give details of the exact questions.

\section{Outcomes of student run clinics}

Only one of the studies (39) reported solely on clients' experiences of attending a SRC as an outcome measure (Table 3 ). The remaining four studies $(34,35,36,38)$, reported solely upon students' experiences of engaging in a SRC. No other outcomes were reported and there were no reports of any adverse outcomes.

\section{Client satisfaction}

Ellet et als' (39) client satisfaction survey of 60 clients who attended a SRC found generally high levels of satisfaction. Hours of operation and wait times were rated as good to excellent by more than half of the participants, while nearly all participants rated friendliness of staff, amount of time spent with the student, time spent with the supervising doctor, lab services and medications provided as good to excellent. (see Table 3).

Some aspects of care were not highly rated. For example, over $36 \%$ of participants surveyed rated hours of operation and waiting times as poor or fair. Other areas rated as poor to fair were friendliness (4\%), time spent with student or supervising doctor (5\%) and lab services and medications (18\%). However, despite claiming an $87 \%$ response rate overall, it must be highlighted that the response rate to the latter two questions within the survey (ie; time spent with student or supervising doctor and lab services and medications) was low, at just $32 \%$. Overall, the majority of clients were very satisfied with the services of the SRC. Services that clients felt could be improved were, waiting times, opening hours, translation services and requests for additional specialist services (39).

\section{Educational outcomes}

Warner et al (38), found that students valued the SRC experience and that it gave them appropriate learning opportunities in a supportive and low stress environment. Furthermore, all demonstrated improved accuracy and performance of their practice. The researchers noted that they used a Likert scale to rate students responses to, how they felt about interdisciplinary collaboration, the learning environment, practising a discipline specific clinical skill, the value of the experience and the interaction with participants. Whilst the use of a five point Likert scale is recorded, the paper contains no empirical data to confirm or refute the findings presented. 
Clark et al (34) also used a five point Likert scale to rate students responses to the learning environment, practice discipline specific skills, value of the experience, learning new skills and collaboration with other disciplines. Preclinical students rated all four statements higher than any other student group with a mean value of 4.8 across all statements. Clinical students and pharmacy students rated 4.5-4.6 across three of the statements and just 4.4 respectively for having contributed to their personal growth. Finally, public health students mean Likert value for having contributed to professional growth was 3.3, personal growth 4.7, increased understanding of bio psychosocial issues 3.7 and a mean value of 4.7 would participate again. Qualitative data extracted from students written and verbal reflections, suggest that students who participated in a SRC developed better social awareness, improved compassion and empathy, increased teamwork skills and confidence.

Similar themes emerged from an informal evaluation project by Copley et al (35) were they reported that students who engaged with SRC left with a broader understanding and awareness of clients healthcare needs, an increased understanding of interprofessional working and that SRC were effective at integrating theory into practice and more effective in improving students' education than other clinical learning environments. However, Gance-Cleveland and Gilbert (36), recommend a combination of traditional clinical experiences and SRCs in order for students to develop to their full potential. The evaluation was carried out by means of questionnaires and emerging themes from these questions were that SRCs within the faculty site were seen to be effective for identifying environmental factors $43 \%$, generating research $55 \%$, assessment of need and improving care planning $80 \%$ and $60-80 \%$ found the site more helpful than outside clinical sites. However, no outcome data were presented within the paper to confirm or refute these claims.

Two studies presented students and or facilitators' views of the perceived benefits and challenges of student led clinics $(35,37)$. Major benefits reported were that it increased the number of placements for students, promoted inter professional learning and developed teamwork skills. Challenges were the pressures on time to commit to the planning and evaluating of student learning.

\section{Discussion}

This review aimed to identify the current state of knowledge surrounding SRC and to further assess whether a student run clinic could be an option for enhancing midwifery education and the postnatal experience of women in the UK. Existing literature on the value of SRCs is limited and only six studies were included in the review $(34,35,36,37,38,39)$. The one previous review that has considered the effectiveness of SRC found limited quality evidence and concluded in 2009 that SRCs are still evolving as incubators for enriching the educational knowledge of students and for meeting the needs of disadvantaged groups (27). Although this review has updated the quantity of research evidence, the quality of this evidence remains poor.

All of the studies included in this review had small sample sizes, preventing generalising of the findings to the wider population. In addition none of the studies included in the review had comparison groups and therefore it is difficult to assess if SRCs do improve competencies and skills of students above and beyond other clinical learning environments. Furthermore, the fact that three of the studies were carried out in the USA and two in Australia makes it difficult to apply the findings to healthcare and in particular, midwifery education in the UK.

However, despite the limitations of the evidence presented it appears that a SRC may provide a valuable health care service to clients who cannot access traditional care through any other means ${ }^{39}$. 
This review therefore supports the growing evidence that SRCs do provide a valuable health care service for disadvantaged groups, who may otherwise have no access to care. Unfortunately with only one paper reporting directly on client experiences of attending a SRC (39) caution is needed in applying the findings more widely and, in particular, the potential for a SRC as a means of providing effective postnatal care to women needs further exploration.

All of the other studies included in the review focused upon students' experiences of engaging in SRC $(34,35,36,37,38)$ and whilst the heterogeneous nature of the studies made combining them to gain consensus impossible, evidence was found in all of them that student run clinics, appear to provide innovative educational learning opportunities, which may enhance leadership and communication skills in students who engage with them.

It is also clear that the operation of SRC does depend upon having oversight by qualified and experienced practitioners, without which students would have difficulty in fulfilling their role, mainly due to their lack of experience in clinical care (29). This was raised by one of the studies as being a challenge (35), particularly in terms of time constraints to plan and evaluate student learning. However, it would not pose any additional issues for transferability into a student midwife run clinic here in the UK, as the NMC (6) requirements ensures that all student midwives are supervised at all times by fully qualified mentors whilst in the practice environment. In fact it could potentially alleviate the pressure upon the student/mentor ratio and increase the number of practice placements, which as discussed earlier is becoming an increasing issue.

In the absence of any current literature on the impact of capacity issues it is clear that national strategies to increase student numbers requires further investigation, and the implementation of a SRC could possibly provide a solution. However, before the added value of increasing placement capacity can be assessed further research is needed to ascertain whether SRC could be an effective contribution to midwifery education and provide an efficient and effective postnatal service to women who use it.

\section{$\underline{\text { Limitations }}$}

To the authors' knowledge this is the first systematic review to investigate whether a student midwife run postnatal clinic would be a valuable addition to midwifery education here in the UK. Whilst this review was rigorously undertaken there were some limitations. Firstly this review did not include nonEnglish written papers and therefore we are unable to assess the effectiveness of SRCs in non-English speaking settings and their perceived value.

\section{Conclusion}

Improving educational outcomes, for our next generation of midwives whilst ensuring the quality of post natal care provision for women, is an on-going challenge. Whilst this review highlights some evidence that SRC are satisfying the needs and expectations of clients and, positively contributing to students' educational experiences, further research is needed before we can be confident of their contribution to the experience of women in the postnatal period and that of midwifery education here in the UK. Further research is therefore recommended to explore student midwives current exposure to post natal care learning opportunities and whether facilitating a post natal student run clinic can improve their educational outcomes and provide an efficient and effective use of resources that satisfy women who use them. 


\section{Funding}

This study was not directly funded; however a period of internship was awarded by the National Institute of Health and Research (NIHR) to one of the authors which enabled the time to undertake this study. 


\section{References}

1. Nursing and Midwifery Council (NMC). Midwives rules and standards. London: Nursing \& Midwifery Council; 2012

2. Cheng CY, Fowles ER, Walker LO. Postpartum Maternal Health Care in the United States: A Critical Review. Journal of Perinatal Education. 2006; 15(3): 34-42.

3. Health Canada. Canada's Health Care Providers, 2000-2009: A Reference Guide. Health Canada: Canada; 2000.

4. Rayner JA, McLachlan HL, Forster DA, Peters L, Yelland JA. Statewide review of postnatal care in Victoria, Australia. BMC Pregnancy and Childbirth. 2010; 5(10): 26.

5. National Institute for Clinical Excellence (NICE). Routine postnatal care of women and their babies. NICE: London; 2006.

6. Nursing and Midwifery Council (NMC). Standards for pre-registration midwifery education. London: Nursing \& Midwifery Council; 2009.

7. Demott K, Bick D, Norman R, Ritchie G, Turnbull N, Adams C, Barry C, Byrom S, Elliman D, Marchant S, Mccandlish R, Mellows H, Neale C, Parkar M, Tait P, Taylor C. Clinical Guidelines And Evidence Review For Post Natal Care: Routine Post Natal Care Of Recently Delivered Women And Their Babies. London: National Collaborating Centre for Primary Care and Royal College of General Practitioners; 2006.

8. Department of Health (DOH). Report of the expert maternity group the Cumberlege Report, Changing Childbirth. HMSO: London; 1993.

9. Department of Health (DOH). National service framework for children, young people and maternity services (NSF). HMSO: London; 2004.

10. Department of Health (DOH). Every Child Matters: Sure Start Childrens Centres Practice Guidance. Department for Education and Skills: Nottingham; 2006.

11. Royal College of Midwives (RCM). Standards for pre-registration midwifery education. RCM: London; 2010.

12. Beake A, Rose V, Bicke D, Weavers A, Wray J. 2010. A qualitative study of the experiences and expectations of women receiving in-client postnatal care in one English maternity unit. BMC Pregnancy and Childbirth 2010; 10(70).

13. Shaw E, Levitt C, Wong S, Kaczorowski J and the McMaster University Postpartum Research Group. Systematic review of the Literature on Postpartum care to improve Maternal Parenting, Mental Health, Quality of Life and Physical Health. Birth. 2006; 33(3): 210-220. 
14. Brown S, Small R, Faber B, Krastev A, Davis P. Early postnatal discharge from hospital for healthy mothers and term infants. Cochrane Database of Systematic Reviews. Art. No: CD002958; 2002

15. Escobar GJ, Braveman PA, Ackerson L, Odouli R, Coleman-Phox K, Capra AM, Wong C, Lieu TA. A randomized comparison of home visits and hospital-based group follow-up visits after early postpartum discharge. Paediatrics. 2001; 108(3): 719-727.

16. Gagnon AJ, Edgar L, Kramer MS, Papageorgiou A, Waghorn K, Klein MC. A randomised trial of a program of early discharge with nurse visitation. American Journal of Obstetrics and Gynecology.1997; 176(1): 205-211.

17. Lieu TA, Braveman PA, Escobar GJ, Fischer AF, Jensvold NG, Capra AM. A randomised comparison of home and clinic follow-up visits after early postpartum hospital discharge. Paediatrics. 2000; 105(5): 1058-1065.

18. National Federation of Women's Institute (NFWI). Support overdue: Women's experiences of maternity services. NFWI: London; 2013.

19. Brodribb W, Zadoroznyj M, Dane A. The views of mothers and GPs about postpartum care in Australian general practice. BMC Family Practice. 2013; 14: 139.

20. European Union Directives (EU).

http://ec.europa.eu/internal market/qualifications/policy developments/legislation/index e

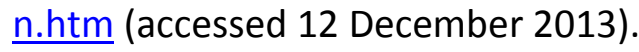

21. Elliott M. Clinical education: a challenging component of undergraduate nursing education. Contemporary Nurse. 2002; 12(1): 69-77.

22. Murray SC, Williamson GR. Managing capacity issues in clinical placements for preregistration nurses. Journal of Clinical Nursing. 2009; 18: 3146-3154.

23. Andrews $M$, Brewer M, Buchan $T$, Denne A, Hammond J, Hardy G, Jacobs L, McKenzie L, West S. Implementation and sustainability of the nursing and midwifery standards for mentoring in the UK. Nurse Education in Practice. 2010; 10(5): 251-255.

24. Brooks, N and Moriarty, A. Implementation of a peer-support system in the clinical setting. Nursing Standard. 2009; 23(27).

25. Hutchings A, Williamson G R, Humphreys A. Supporting Learners in clinical practice: capacity issues. Journal of Clinical Nursing. 2005; 14: 945-955.

26. Marsh W. Giving you Every Reason to SMiLE. Practising Midwife. 2013; Oct

27. Meah YS, Smith EL, Thomas DC. Student-Run Health Clinic: Novel Arena to Educate Medical Students on Systems-Based Practice. Mount Sinai Journal of Medicine.2009; 76: 344356. 
28. Scott A, Simpson BA, Long JA. Medical Student-Run Clinis: Important Contributors to Client Care and Medical Education. Society of Internal Medicine.2006; 22: 352-356.

29. Buchanan D and Witlen R. Balancing Service and Education: Ethical Management of Student-Run Clinics. Journal of Health Care for the Poor and Undeserved.2006; 17(3): 477-485.

30. Richardson WS, Wilson MC, Nishikawa J, Hayward RSA . The well built clinical question: a key to evidence based decisions. American College of Physicians.1995; 123: A-12.

31. Cronin P, Ryan F, Coughlan M. Undertaking a literature review: A step by step approach. British Journal of Nursing. 2008; 17 (1): 38-43.

32. Critical Appraisal Skills Programme (CASP). Making Sense of Evidence Tool: 10 Questions to help you make sense of qualitative research. 2004. www.casp-uk.com (accessed: 12 January 2014).

33. Hannes K, Chapter 4: Critical appraisal of qualitative research. In: Noyes J, Booth A, Hannes K, Harden A, Harris J, Lewin S, Lockwood C (editors), Supplementary Guidance for Inclusion of Qualitative Research in Cochrane Systematic Reviews of Interventions. Version 1 (updated August 2011). Cochrane Collaboration Qualitative Methods Group, 2011. http://cqrmg.cochrane.org/supplemental-handbook-guidance (accessed 12 December 2013).

34. Clark DL, Melillo A, Wallace D, Pierrel S, Buck DS. A Multidisciplinary, Learner Centred, Student-run Clinic for the Homeless. Innovations in Family Medicine Education. 2003; 35(6): 394-397.

35. Copley JA, Allison HD, Hill AE, Moran MC, Tait JA, Day T. Making interprofessional education real: a university clinic model. Australian Health Review. 2007; 31 (3): 351-357.

36. Gance-Cleveland B and Gilbert LH. Connecting classroom clinic and community:pediatric nurse practitioner student and faculty assessment of clinical experience at faculty practice sites. Journal of Nursing Education. 2001; 40(4): 187-190.

37. Smith S, Johnson M, Rodriguez N, Moutier C, Beck E. Medical Student Perceptions of the Educational Value of a Student-Run Free Clinic. Family Medicine. 2012; 44(9): 646-649.

38. Warner P. Jelinek,H. Davidson PM. A university clinic: an innovative model for improving clinical practice. Australian Journal of Advanced Nursing. 2010; 27(4): 38-42.

39. Ellett JD, Campbell JA, Gonsalves WC. Client Satisfaction in a Student-run Free Medical Clinic. Innovations in Family Medicine Education. 2010; 42(1): 16-18.

40. Kerstin MP, Dole RL, Lattanzi JB. A Case Report of a Student-Led Pro Bono Clinic: A Proposed Model for Meeting Student and Community Needs in A Sustainable Manner. Physical Therapy. 2011; 91(11): 1627-1635. 


\section{Bibliography}

Bick D, Rose V, Weavers A, Wray J, Beake S. Improving inclient postnatal services: midwives views and perspectives of engagement in a quality improvement initiative. BMC Health Services Research. 2011; 11:(293).

Bashour HN. Effect of Postnatal Home Visits on Maternal/Infant Outcomes in Syria: A Randomized Controlled Trial. Public Health Nursing. 2008; 25(2): 115-125.

Department of Health (DOH). Our health, our care, our say : A new direction for community services. HMSO: London;2006.

NHS Employers (2006). www.nhsemployers.org/workforce/workforce-881cfm (accessed 2 May 2012).

Roberts D. Learning in clinical practice: the importance of peers. Nursing Standard. 2008; 23 (12): 35-41.

Wilson J. Bridging the theory practice gap. Australian Nursing Journal. 2008; 16(4): 25. 


\section{Fig.1 - Summary of final selection}

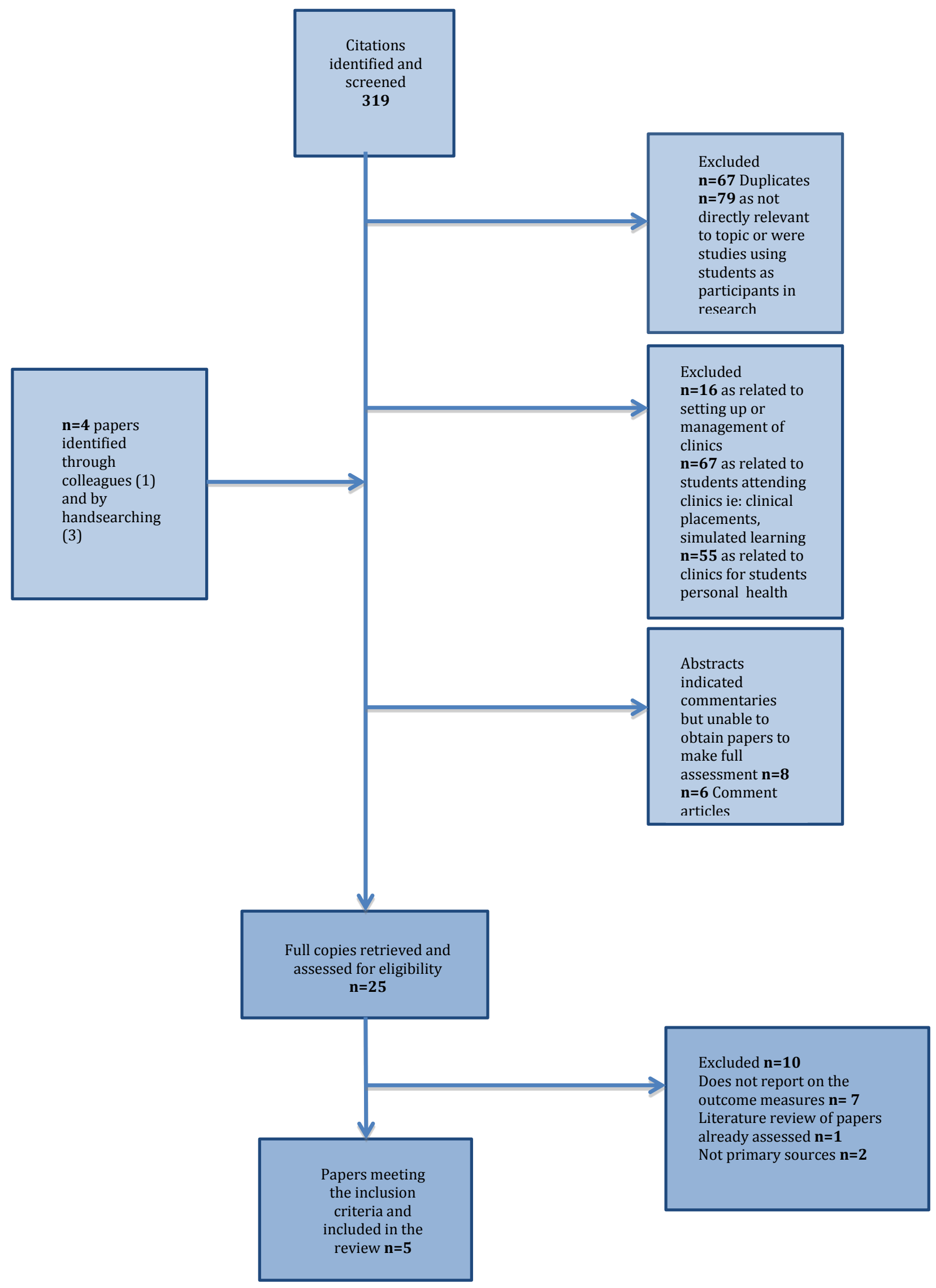


Table 1 - Characteristics of selected studies

\begin{tabular}{|c|c|c|c|c|c|c|}
\hline \multirow[t]{2}{*}{ Source } & \multirow[t]{2}{*}{ Location } & \multirow[t]{2}{*}{ Intervention } & \multirow[t]{2}{*}{ Control } & \multirow[t]{2}{*}{ Methods } & \multicolumn{2}{|c|}{ Outcome measures } \\
\hline & & & & & Education & Clients \\
\hline \multicolumn{7}{|l|}{ Quantitative studies } \\
\hline $\begin{array}{l}\text { Ellet et al, } \\
2010\end{array}$ & USA & $\begin{array}{l}\text { Student run free } \\
\text { medical clinic }\end{array}$ & None & $\begin{array}{l}\text { Web based } \\
\text { surveys }\end{array}$ & No & Yes \\
\hline $\begin{array}{l}\text { Warner et al, } \\
2010\end{array}$ & Australia & Student run clinic & None & Questionnaire & Yes & No \\
\hline $\begin{array}{l}\text { Smith et al, } \\
2012\end{array}$ & USA & $\begin{array}{l}\text { Student run free } \\
\text { medical clinic }\end{array}$ & None & $\begin{array}{l}\text { Web based } \\
\text { survey }\end{array}$ & Yes & No \\
\hline \multicolumn{7}{|l|}{ Service evaluations } \\
\hline $\begin{array}{l}\text { Gance- } \\
\text { Cleveland, } \\
2001\end{array}$ & USA & Student run clinic & None & Survey & Yes & No \\
\hline $\begin{array}{l}\text { Clark et al, } \\
2003\end{array}$ & USA & $\begin{array}{l}\text { Student run free } \\
\text { medical clinic }\end{array}$ & None & Questionnaires & Yes & No \\
\hline $\begin{array}{l}\text { Copley et al, } \\
2007\end{array}$ & Australia & Student run clinic & None & $\begin{array}{l}\text { Anonymous } \\
\text { Questionnaires }\end{array}$ & Yes & No \\
\hline
\end{tabular}


$\underline{\text { Table } 2 \text { - Different models of service within SRC }}$

\begin{tabular}{|c|c|c|c|c|}
\hline Source & Intervention & $\begin{array}{l}\text { Discipline of } \\
\text { students }\end{array}$ & $\begin{array}{l}\text { Location of } \\
\text { clinic }\end{array}$ & Facilitated by \\
\hline $\begin{array}{l}\text { Gance- } \\
\text { Cleveland } \\
2001\end{array}$ & Student run clinic & $\begin{array}{c}\text { Student paediatric } \\
\text { nurse } \\
\text { practitioners }\end{array}$ & $\begin{array}{l}\text { University } \\
\text { based }\end{array}$ & $\begin{array}{l}\text { Faculty preceptors } \\
\text { and } \\
\text { Clinical teaching } \\
\text { associates }\end{array}$ \\
\hline $\begin{array}{l}\text { Clark et } \\
\text { al } 2003\end{array}$ & $\begin{array}{l}\text { Interprofessional, student run } \\
\text { medical clinic }\end{array}$ & $\begin{array}{c}\text { Medical, } \\
\text { pharmacy, public } \\
\text { health, social } \\
\text { work students }\end{array}$ & $\begin{array}{l}\text { Community } \\
\text { based in } \\
\text { a homeless } \\
\text { shelter }\end{array}$ & $\begin{array}{l}\text { Faculty advisors from } \\
\text { each school, faculty } \\
\text { doctors, faculty } \\
\text { pharmacist and a } \\
\text { clinical psychologist }\end{array}$ \\
\hline $\begin{array}{l}\text { Copley et } \\
\text { al } 2007\end{array}$ & $\begin{array}{l}\text { Interprofessional, student run, } \\
\text { occupational therapy and } \\
\text { speech and language therapy } \\
\text { clinic }\end{array}$ & $\begin{array}{c}\text { Occupational } \\
\text { therapists, speech } \\
\text { therapists, }\end{array}$ & $\begin{array}{l}\text { University } \\
\text { based }\end{array}$ & $\begin{array}{l}\text { University clinical } \\
\text { educators from each } \\
\text { field }\end{array}$ \\
\hline $\begin{array}{l}\text { Ellett et } \\
\text { al } 2010\end{array}$ & $\begin{array}{l}\text { Interprofessional student run } \\
\text { medical clinic }\end{array}$ & $\begin{array}{c}\text { Medical, } \\
\text { physiotherapy and } \\
\text { pharmacy students }\end{array}$ & $\begin{array}{l}\text { Community } \\
\text { based free clinic } \\
\text { to uninsured } \\
\text { population }\end{array}$ & $\begin{array}{l}\text { Supervising physician } \\
\text { and faculty advisors }\end{array}$ \\
\hline $\begin{array}{l}\text { Warner } \\
\text { et al } 2010\end{array}$ & $\begin{array}{l}\text { Interprofessional student run } \\
\text { cardiovascular screening clinic }\end{array}$ & $\begin{array}{l}\text { Nursing and podiatry } \\
\text { students }\end{array}$ & $\begin{array}{l}\text { University } \\
\text { based }\end{array}$ & $\begin{array}{l}\text { Academics from } \\
\text { nursing, podiatry or } \\
\text { laboratory staff }\end{array}$ \\
\hline $\begin{array}{l}\text { Smith et } \\
\text { al } 2012\end{array}$ & Student run clinic & Medical & $\begin{array}{l}\text { University } \\
\text { based }\end{array}$ & $\begin{array}{l}\text { Faculty educators } \\
\text { from the University }\end{array}$ \\
\hline
\end{tabular}




\section{Table 3 - Key findings of selected studies reporting outcomes}

\begin{tabular}{|c|c|c|}
\hline Source & Educational outcomes & Client satisfaction \\
\hline $\begin{array}{l}\text { Ellet et al, } \\
2010\end{array}$ & Not measured & $\begin{array}{l}\text { Clients seen at this SRC are highly satisfied with the care } \\
\text { they receive including: } \\
\text { - Friendliness of students ( } 94 \% \text { good/excellent) } \\
\text { - Hours of operation ( } 59 \% \text { good/excellent) } \\
\text { - Waiting time ( } 64 \% \text { good/excellent) } \\
\text { - Medications provided ( } 91 \% \text { good/excellent) } \\
\text { - Time spent with student ( } 94 \% \text { good to } \\
\text { - } \quad \text { Time spent with supervising doctor ( } 95 \% \\
\text { good/excellent) }\end{array}$ \\
\hline $\begin{array}{l}\text { Gance- } \\
\text { Cleveland, } \\
2001\end{array}$ & $\begin{array}{l}\text { Students found the practice site helpful in: } \\
\text { - Generating nursing theory (57\%) } \\
\text { - Assessing health needs of vulnerable } \\
\text { groups ( } 80 \%) \\
\text { - Generating research questions ( } 55 \%) \\
\text { - Integrating theory \& research into } \\
\text { practice (55\%) } \\
\text { Majority }(60-80 \%) \text { found the practice sites } \\
\text { more helpful than outside clinical sites. }\end{array}$ & Not measured \\
\hline $\begin{array}{l}\text { Clark et al, } \\
2003\end{array}$ & $\begin{array}{l}\text { Students who engaged valued the programme. } \\
\text { Felt it: } \\
\text { - contributed to both personal and } \\
\text { professional development; } \\
\text { - increased understanding of bio } \\
\text { psychosocial issues; } \\
\text { - developed their compassion, empathy } \\
\text { and social awareness. }\end{array}$ & Not measured \\
\hline $\begin{array}{l}\text { Copley et al, } \\
2007\end{array}$ & $\begin{array}{l}\text { SRC's are successful in providing universities } \\
\text { with opportunities to promote } \\
\text { interprofessional learning. }\end{array}$ & Not measured \\
\hline $\begin{array}{l}\text { Warner et al, } \\
2010\end{array}$ & $\begin{array}{l}\text { All students felt the experience of running a } \\
\text { clinic was worthwhile. It enabled them to: } \\
\text { - practice skills in a supportive } \\
\text { - environment and from people they trust; } \\
\text { - learn from each other; } \\
\text { - imply theory to practice; } \\
\text { improve accuracy of procedural } \\
\text { performance i.e. vital signs. }\end{array}$ & Not measured \\
\hline $\begin{array}{l}\text { Smith et al, } \\
2012\end{array}$ & $\begin{array}{l}90 \% \text { of students who returned their } \\
\text { questionnaires felt that engaging with a SRC } \\
\text { had been a valuable addition to their } \\
\text { education. }\end{array}$ & Not measured \\
\hline
\end{tabular}

